\title{
O PORTUGUÊS DE CONTATO FALADO PELOS ÍNDIOS KAMAYURÁS
}

\section{RESU MO}

\author{
M aria $\mathrm{G}$ uadal upedeC astro* \\ Lídia Spaziani ** \\ M aria Célia Lima-H ernandes***
}

Com base em corpus de língua portuguesa falada pelos índios Kamayurás, discute-se a pertinência de duas teses lingüísticas - evolucionista e adstrativista - que explicariam os contatos. A partir dessa discussão evidenciam-se as interferências lingüísticas decorrentes de tais contatos.

Palavras-chave variaçãolingüística; por tuguês decontato; aspectos contrastivos.

\section{ABST RACT}

This paper is based on the corpus of the Portuguese Language spoken by the $K$ amayurás Indians. The evolutionist and adstractivist linguistic relevances, which could explain these contacts, are discussed. From these discussions, the result from these contacts - the linguistic interferences - are evidenced.

$\mathrm{K}$ ey w ords: lingui stic variati on; P ortuguese of contact; contrasti veaspects.

\section{0 panorama lingüístico: um inventário por se fazer}

Pelas estimativas oficiais, temos cerca de 7.000 a 6.000 línguas faladas no mundo hoje, muitas das quais se enquadram como dialetos (W URM, 1996). Pelo quadro histórico bastante conhecido, sabemos que muitas línguas estão mortas, tais como o latim, o grego antigo e 0 sânscrito. É certo, contudo, que sobrevivem de forma artificial, presas às exigências contextuais e circunstanciais de algumas poucas pessoas.

Esse fato fez com que muitos estudiosos, nos últimos anos, voltassem a atenção para os direitos lingüísticos de comunidades minoritárias. Tal preocupação prende-se ao fato de que muitos povos autóctones abandonam suas línguas por força das necessidades subjacentes à comunidade de contato. Assim, muitas línguas encontram-se ameaçadas de extinção, pois sobrevivem apenas nos falares de idosos.

0 mesmo fenômeno tem aos poucos se revelado no mundo indígena, uma vez que o contato com o mundo civilizado trouxe uma série de itens lexicais completamente inovadores na visão autóctone; muitas necessidades urbanas passaram a compor o quadro rural em que vivem esses indígenas.
* Doutoranda em Lingüística (UNICAMP) e professora da UN IN OVE.

** M estranda em Educação (UNINOVE) e professora da UNINOVE.

***Doutoranda em Lingüística (FFLCH/USP) e professora da UN IN OVE/ USP. 
0 contato lingüístico, nessa perspectiva, acarreta forte impacto sobre a língua autóctone, gerando muitas vezes, numa fase inicial, 0 surgimento de uma língua chamada pidgin ${ }^{1}$ e, na sucessão desta, uma língua criolla, cuja base é o superestrato ${ }^{2}$. Em conseqüência, a língua de substrato pouco a pouco é substituída até ser extinta por completo, a exemplo do que ocorreu com a língua indígena pataxó no Brasil.

\section{Contatos no Alto $X$ ingu e hipóteses lingüísticas}

N o Alto Xingu, área brasileira de preservação, de 26.000 quilômetros quadrados, sobrevivem oito línguas autóctones: Kamayurá e Aweti (tronco tupi); Waurá, M ehinako e Yawal apiti (tronco A rawak); K alapalo, Kuikuro e Matipu (tronco Caribe), e Trumai (língua isolada). $\mathrm{N}$ essa grande área, a Funai (Fundação $\mathrm{N}$ acional Indígena) é peça fundamental na preservação da cultura daqueles povos. A despeito de todo o cuidado que se possa ter, o contato lingüístico é inevitável. Assim, dáse início a um processo itinerante, com uma língua pidgin, até chegar a um grau de fluência proficiente na língua de superestrato.

Os efeitos desse contato lingüístico tornaram-se alvo de freqüentes investigações por parte de lingüistas de todo o mundo. Alguns pesquisadores, a exemplo de Macedo (2000), entendem os usos 'imperfeitos' como reflexos de graus diferenciados de domínio lingüístico associados à evolução da língua portuguesa (tese evolucionista ou diacrônica) ${ }^{3}$. Em contrapartida, outros autores estão atentos às interpenetrações no momento do contato (tese adstrativista ou sincrônica), detendo-se, sobretudo, na tarefa de descrever os dois sistemas lingüísticos envolvidos que, como Spaziani \& al. (2000), após a descrição da variedade portuguesa de contato utilizada pelos kamayurás, chegaram à conclusão de que os fenômenos rotulados como corruptelas ou desvios também estão presentes na variedade rural, chamada variedade popular. ${ }^{4}$

Em decorrência dessa constatação, as autoras 5 passaram a recoIher evidências que dessem conta de responder à seguinte questão: seria a variedade popular um grau mais baixo de fluência lingüística natural no processo de aquisição de segunda língua ou seria ela a variedade de contato, presente na região rural em que viviam os indígenas? Ao final, as citadas autoras estabeleceram o contraste entre os sistemas lingüísticos estudados e notaram 0 al to grau de confluência entre as variedades.

As respostas a essas questões atingem de forma direta dois eventos políticos brasileiros. 0 primeiro diz respeito à Convenção $107^{6}$, da
${ }^{1}$ Para alguns autores, a exemplo de TARALLO \& ALKM IN (1987), o termo pidgin originase da corruptela da palavra business e confere a uma língua o status de 'arrebento' lingüístico, ou seja, primeiro contato entre duas línguas. Difere-se da língua criolla, entre outros aspectos, pela existência de falantes nativos, condição sine qua non para que seja percebida como língua nativa. ${ }^{2}$ Também conforme TARA $\amalg O \&$ A LKM IN (1987), superestrato é 0 rótulo lingüístico que identifica a língua estrangeira que estabelece contato em terras de uma comunidade autóctone. Neste sentido, opõe-se à substrato.

${ }^{3} \mathrm{~A}$ tese evolucionista ou diacrônica aplicada aos contatos lingüísticos tem por fundamento a associação da fluência e da disfluência verbal aos princípios históricos que regem a segunda língua. Esta tese opõe-se à adstrativista ou sincrônica, que prevê interferências simultâneas e recíprocas entre os dois sistemas envolvidos no contato.

${ }^{4} \mathrm{M}$ uitos a utores a firmam que 0 português popular é aquele falado por pessoas da classe social menos favorecida, que a aprendem no convívio familiar (SILVA NETO, 1977:19), portanto de oitiva, e que possuem uma cultura 'rústica'. (AM ARAL, 1920)

${ }^{5}$ Spaziani et al. (2000) procederam ao levantamento de dados de língua falada em três corpora: Emmerich (1984), Rodrigues (1987) e Chahine \& Lima-Hernandes. (1998)

6"Será ministrado às crianças pertencentes a populações interessadas ensino para capacitá-las a ler e a escrever em sua língua materna ou, em caso de impossibilidade, na língua mais comumente empregada pelo grupo a que pertençam". (art.23, da Convenção 107) 
Conferência Geral da Organização Internacional do Trabalho, em seu artigo 23, aprovada pelo Congresso Brasileiro em 1965, e o segundo, à lei 60017, conhecida como Estatuto do Índio, promulgado em 1973.

$\mathrm{N}$ a essência, ambos os eventos têm por objetivo precípuo a preservação cultural indígena, inclusive no que se refere à al fabetização na língua do grupo. Em contrapartida, não é concebível o isolamento indígena, ocorrendo, assim, a aquisição de uma variedade portuguesa semelhante à fala local .

\section{Confluências e divergências entre os sistemas: evidências de contato}

Em que pesem os argumentos decorrentes da tese evolucionista, o número de pontos fônicos convergentes favorece, sobremaneira, a aceitação da tese adstrativista, uma vez que na interação de falantes de línguas distintas há que se observar a emergência de códigos de contato.

Em suma, não se podem discutir contatos de povos sem se preverem os contatos lingüísticos e usos subjacentes, mais evidentemente representados pelos hábitos fônicos pertinentes. Desse modo, a variedade portuguesa falada pelos kamayurás não pode ser compreendida como uma fase 'imperfeita' de fluência, e sim como uma interpenetração de hábitos lingüísticos, que têm como resultado a interferência mútua.

Segundo Romaine (1995), em muitas situações de contato lingüístico, pode ocorrer a emergência de um novo sistema, que seja resultante ou da mistura ou da convergência entre aspectos dos dois sistemas envolvidos. Nessa perspectiva, uma língua aprendida em situação de contato certamente reterá el ementos da língua materna como vestígios sobreviventes na segunda língua aprendida.

Algumas evidências que atestam o postulado de Romaine podem ser encontradas no trabal ho de Cavalcanti (1999). Essa autora, ao investigar a língua da tribo A purinã, notou que marcas da língua ancestral, já extinta, resistiam na atual língua daquela comunidade.

Mollica (1997) também investigou as variedades de contato e observou que aspectos prototípicos da primeira língua apareciam com freqüência na variedade portuguesa, tal como ocorre nos processos de formação de línguas pidgin e criollas.

Outros autores, a exemplo de Roncarati \& Mollica (1997), analisaram a variedade falada pelos kamayurás e yawalapitis a fim de investigarem a redução fonêmica na sonorização (/f/ > /v/; /p/ > /
7"Regula a situação jurídica dos índios e silvícolas e das comunidades indígenas, com o propósito de preservar a sua cultura e integrá-los, progressiva e harmoniosamente, à comunhão nacional" (artigo 1, da lei 6001). 
b/) e no ensurdecimento consonantal $(/ z />/ s / ; / d />/ t /)$. $0 b-$ servaram que esses grupos de falantes associavam a ocorrência de ensurdecimento, fenômeno atípico da língua portuguesa, aos falantes mais velhos.

Mollica (1997) pesquisou também os usos lingüísticos dos índios para o grau de fluência em L2. Ela observou que os seguintes fenômenos são apresentados no processo de aquisição da língua : assimilação, síncope do fonema /r/ medial, prótese do fonema /a/, aférese do fonema /a/, monotongação, substituição de I > $r$ final.

Três anos mais tarde, Macedo (2000) identificou casos de apagamento do determinante e associou-os à fala dos índios mais velhos. Também de acordo com a autora, a língua tupi assumiu a ordem OV, que pode prover interferência durante 0 aprendizado da língua portuguesa, cuja ordem prototípica é SVO.

Afora a inovação do método quantitativo oferecido pelas autoras citadas, A maral (1920) já evidenciava as características tidas como típicas daquela variedade caipira, que àquela época não era distinguida da variedade popular.

\section{Especificidades do português falado pelos K amayurás}

Os fenômenos de alteração fônica caracterizam a variedade portuguesa de contato e podem ser segmentados em dois grandes conjuntos: interferências da língua de superestrato (português); interferências da língua de substrato (kamayurá).

No primeiro conjunto, agrupam-se fenômenos típicos da língua portuguesa desde sua origem no latim vulgar, podendo ser apreciados na literatura lingüística sob os rótulos de assimilação, aférese, metátese, ditongação, nasalização, desnasalização, alçamento/ redução vocálica, apócope, prótese e síncope.

As explicações que subjazem a esses usos dão-se no plano da aquisição da segunda língua pelos kamayurás. 0 corre que a variedade de contato no Alto Xingu é variedade rural (português popular ou caipira), que tem por peculiaridade a manutenção dos vestígios históricos, haja vista que, diacronicamente, esta variedade não sofreu imposições da norma culta por meio da escola.

A transposição sonora representa um fenômeno pouco recorrente no português usado pelos indígenas. Tais casos podem ser representados nos exemplos em que ocorre a mudança de um fonema 
consonantal /r/ dentro da mesma sílaba, comumente rotulado de metátese:

(a) ela so escutano, fica assim. Depois ele pregunta, depois eu priguntei pra [Sukuri9, p.17]

(b)e, pra acampamento dele, drumiu um, vai sai, desceu lá no Morena, né? [Sukuri3, p.2]

(c) quando esse água fica freveno muito [Sapaim2, p.5]

Outro fenômeno recorrente na variedade de contato é o apagamento sonoro (36\%), que tanto operou com um único fonema do vocábulo quanto com sílabas. Também manifestou-se na redução dos ditongos /ow/ (17\%) e /ãw/ (9\%):

(d) ele tá...tá co...ele ta cum menos [Takara21, p.2]

(e) tão foi lá...lá Campo, noise...lá no Campo [Sukuri8, p.9]

(f) vai dumi. Quando saiu so dona di K waryp vai sai, né. [Sukuri7,p.3]

Outro fenômeno muito recorrente no português de contato é 0 acréscimo sonoro (18\%) que, do ponto de vista dos fonemas envolvidos, compõe um quadro bastante variado. Assim, encontram-se alterações envolvendo os seguintes fonemas: /a/ seguido de verbo e /i/ seguido de substantivo e advérbio. Afora esses fonemas, encontramos também casos de acréscimo vocálico, gerador de ditongos.

(g) aí isso. Aí depois/ aí eu alevantei, né? [Takuma20, p.4]

(h) nóis pega carru, né? [Sukuri8, p.9]

(i) cinco hora vai saí outro saiu mais pouco né, maisi pouco, então dona di $K$ waryp ta comida... Sukuri 7, p.1]

A substituição sonora também caracteriza a variedade discutida, constituindo o fenômeno de alteração fônica mais recorrente (45\%). As substituições que decorrem de tal fenômeno envolveram tanto fonemas vocálicos em al çamento (55\%) quanto fonemas surdos que se sonorizaram $(45 \%)$ :

(j) Orlando num fala, ele fala, né, Orlando num fala não, A ritana tamém ah, O rlando não qué escudá... [Sukuri8, p.2]

$(\mathrm{k})$ mulhé tem medo...plantá batata planta miyu, planta mandioca [Sukuri3, p.1]

(I) eli voi...língua de $\mathrm{K}$ alapalo [Sukuri7,p.6]

No segundo conjunto, estão os fenômenos atípicos no Português, que refletem alterações fônicas que não fazem parte da história da formação da língua portuguesa. A explicação para tais usos na variedade L2 falada pelos kamayurás se dá no plano de interferências do 
substrato lingüístico.

Esses fenômenos incluem alterações por substituição (92\%) e apagamento (8\%), podendo ser exemplificados por:

(m) depois chamo o maribundo, né, não(...) chama ele pra, pra enterrá ele [Sapaim 2,p.5]

(n)tão eu fala tamem meua língua. [Sukuri 7,p.13]

(o) o canoa M ei/K amyurá chegô lá onde tá o canoa, né, pegaru tudo cripe, pegô tutu gripe [Takuma20,p.11]

Como pudemos até aqui perceber, há uma linha tênue que separa duas variedades. Essa linha torna-se completamente opaca no caso dos dados analisados, uma vez que os casos identificados sobrepõem-se, constituindo um conjunto de variantes coeso.

\section{5. À guisa de conclusão}

Ainda que muitos lingüistas façam questão de separar o diale to caipira do falar caboclo, observa-se a existência de um al to grau de convergência. Parece possível defender que as diferenças resumem-se à aquisição da língua pelos falantes, já que essas variedades são interpenetráveis e mutuamente compreensíveis.

Em ambas ocorrem alterações fônicas - rotacismo, metátese, monotongação, prótese, assimilação, redução de vogal átona final e apagamento do / $r$ / final - e esses fenômenos indicam claramente que a aquisição da língua é resultado dos contatos sociais entre indígenas e pessoas da região rural no Alto $X$ ingu.

Em contrapartida, apresenta-se nos usos do português falado pel os kamayurás, ainda que em menor recorrência (6\%), a interferência de elementos de substrato lingüístico, comum no nível de fluência dos indivíduos observados.

Por fim, ao se analisar o fenômeno de mescla intercomunidade, três perspectivas devem ser adotadas: a da sociedade como el emento global, a do indivíduo na mesma sociedade e, por último, a perspectiva estritamente lingüística (TARALLO \& ALK MIN 1987). Assim procedemos, ao inserirmos a língua pidgin, como primeira etapa do contato lingüístico, dependente, contudo, da existência de falante nativo para ascender ao rótulo de língua criolla, fase constatada nos falares de vários índios da tribo K amayurá. 


\section{Referências bibliográficas}

Amaral, Amadeu (1920) 0 dialeto caipira. São Paulo: Casa Ed. 0 livro. CÂmara J R., J oaquim Mattoso. (1975) D ispersos. Rio de Janeiro: FGV. CavalCANTI, M.C. Estudos sobre educação bilíngüe e escolarização em contexto de minorias lingüísticas no Brasil. In: D ELTA (15), 1999 (pp.385-417).

Chahine, Sumaia \& Lima-Hernandes, Maria Célia (1998). Constituição de córpus de língua fal ada na cidade de São Paulo. In: A nais do II Congresso $\mathrm{N}$ acional deL ingüística eF ilologia. Rio deJ anei ro: CiFEFiL $\&$ UFRJ.

Emmerich, Charlote (1984) A língua de contato no A I to X ingu: origem, forma e função. Tese de doutorado, Faculdade de Letras, UFRJ.

LaBov, W illiam. (1966) The sodial stratification of English in the N ew York City. Washington: Center of Applied Linguistics.

Macedo, Alzira T. (2000) Pidginization and depidginização in the Portuguese of the Upper Xingu. In: Mollica, M.C. \& Martellota, M.E. (org.) A nálises linguísticas: a contribuição deA Izira M acedo. Rio de Janeiro: UFRJ, (pp. 93-105).

MoluıCA, Maria Cećlia. (1997).A quisição de padrões fonológicos variáveis. In: Roncaratti, C. \& Mollica, M.C. (orgs.) Variação e aqui sição. Rio de Janeiro: Tempo Brasileiro, (pp.33-64).

Rodrigues, Angela C.de Souza (1987) A concordância verbal no português popular em São Paulo. Tese de doutoramento, FFLCH, U SP.

Romaine, Suzanne (1995) B ilingualism. Mass: Blackwell, Cambridge.

Ron Caratı, Cláudia \& Mollica, Maria Cecília (1987).Variação e aquisição. Rio de Janeiro: Tempo Brasileiro.

SAID A LI, Manuel (1966) G ramática histórica da língua portuguesa.. São Paulo: M el horamentos.

Si lva N eto, Serafim (1986) Introdução ao estudo da língua portuguesa do B rasil. Rio de J aneiro: Presença.

Spazıanı, Lídia et al. (2000) Linguistic Variation from Spoken Brazilian Portuguese in Caboclo and Caipira. In: $29^{\text {th }}$ A nnual N ewWave Conference A nnais. Michigan: Michigan University.

TARAllo, Fernando \& ALK M IN , Tânia (1987). F alares crioul os: línguas em contato. São Paulo: Ática.

W URM, Stephen A.(1996) A tlas of thew orld's languages in danger of disappearing. Paris/Canberra: Unesco Publishing/Pacific Linguistics. 